\title{
Masculinidades, emociones y crimen en la narrativa policial argentina
}

\author{
Mirian Pino \\ Universidad Nacional de Córdoba \\ mirianpinofly@gmail.com
}

El género policial constituye un objeto de estudio potente para pensar la articulación entre crimen, emociones y masculinidades; como vector teórico metodológico orientativo advierto que la fórmula raigal y sus variantes socioculturales en el nuevo milenio visibilizan una nueva perspectiva de las emociones, a la luz del denominado "giro afectivo" y/o "giro emocional" que se desarrolla en otras disciplinas como las ciencias sociales y la filosofía; Amalia López, prologuista de La politica cultural de las emociones, obra de Sara Ahmed, señala que: "Otra cuestión que merece la pena apuntar en el marco de la actual discusión movilizada por "el giro emocional" tiene que ver con la productividad (o no) de establecer un corte conceptual entre emociones y afectos. Para quienes esta distinción sí es productiva las emociones conformarían un sistema comunicativo integrado por elementos expresivos, fisiológicos, conductuales y cognitivos construido culturalmente" (Greco y Stenner 7).

En su construcción, por lo tanto, habría que tomar en cuenta la intersección de múltiples variables sociales (género, sexualidad, raza, clase, etc) y condiciones espacio-temporales que explican la gran diferencia sincrónica y diacrónica de experiencias de, por ejemplo, miedo o alegría. Mientras que la afectividad implicaría un sistema comunicativo con una inscripción cultural mucho más difusa que Brian Massumi define, haciéndose eco de las filosofías del devenir en Spinoza y Deleuze, como una intensificación del cuerpo. Sin embargo, esta autonomía semiótica del afecto es criticada por quienes, como la propia Sara Ahmed, entienden en esta separación analítica entre emociones y afectividad una reinstalación de la falacia opositiva cultura/naturaleza que ignora el carácter sobredeterminado de los procesos corporales (Hemmings 2005)" (López 4).

Siguiendo a López y Ahmed, no pondré en valor esta dicotomía, ya que la naturaleza de la afectación también es socialmente construida; así infiero que las emociones poseen una dimensión política y sociosemiótica, con lo cual un texto literario puede constituir un importante objeto de estudio. Un primer escalón con respecto a este tema más cercano a la literatura fue el aporte de la semiótica de las pasiones de Jean Parret, quien recorre en Occidente los aportes desde la filosofía. El estudioso belga disocia las pasiones de las emociones, en ambas deja de lado el 


\section{Adiós a las armas}

Despatriarcar América desde la cultura

componente sociocultural para anclarlas desde una perspectiva ontológica; a propósito de lo acotado expresa:

yo considero que la relación de manifestación entre la emoción y la pasión es epistemológica: la pasión es una categoría explicativa, se recostruye y presupone necesariamente a partir de sus manifestaciones, mientras que la emoción es una categoría descriptiva, empíricamente actualizada. Se necesitan estrategias de descubrimiento diferentes en los dos dominios: el dominio de las pasiones es semiótico, el de las emociones psicológico (137).

Estamos aquí, en una primera grada, en la cual el componente social no se advierte. También es preciso acotar que el texto data del interregno 80-90 del siglo $\mathrm{XX}$, momento en el cual todavía no alcanzaba a visibilizarse la articulación epistemológica de las emociones y la sociopolítica. Desde mi perspectiva me interesa cómo las emociones constituyen signos a partir de los cuales desde la literatura es posible leer el mundo, su naturaleza sociocultural; otro de los aportes sustanciales lo constituye el de Emma León que, a partir de Max Scheller, atribuye al ordo amoris, el orden del amor, una jerarquía que circula en la sociedad; la otredad, las alterizaciones en dicho marco teórico poseen un cariz peyorizante y se explican por las relaciones de poder. La alteridad abyecta, anormal construida socialmente puede conducir al otro a la muerte. Este aspecto es fundamental para pensar las nuevas criminalidades, el lugar de crimen en la literatura y cómo el género se "regenera" a partir del componente sociohistórico. ${ }^{1}$

Asimismo, el policial evidencia que no hay crimen sin sujeto, y en un conjunto importante de obras de la literatura argentina es posible advertir que no existe el crimen sin sujetos criminalizados. Es decir, la criminalización también es un constructo cultural, resultante de lo que el socius no solo entiende por crimen sino también cómo lo siente, cómo moviliza sus emociones. Baste pensar en la construcción de la política de la inseguridad del Estado argentino actual y los debates en torno a este, a partir de la sensación del ciudadano ante el temor que posee un rostro en el cual se anuda la racialización colonial del color de piel con la pobreza. Sin duda es el maridaje de las políticas de Estado con los medios masivos los encargados de desatar las políticas públicas de las emociones sociales que luego se reflejan en las urnas. Una alianza de poder echa a funcionar la maquinaria emocional que traspasa de sujeto a sujeto.

Asesinato, neoliberalismo y emociones pensadas como afectaciones, constituyen una red que desata la línea de sentido amor-odio sociocultural y que hacen

1 Otro de los aportes importantes pero que parte de la esfera pública y las emociones lo constituye el Número 24 de la Revista deSignis Emociones en la nueva esfera pública del año 2016, pero en el número citado no hay referencia alguna a trabajos desde el discurso literario. 
blanco en los cuerpos. Esta articulación desencadenará en un número nada despreciable de obras literarias, la historia de las masculinidades y las formas de hacer política del crimen; en esta dirección el género policial brinda una cantera de obras que abarca no solo la narrativa sino también la poesía para problematizar las emociones. Desde los sujetos de enunciación, los valores que portan los personajes, los tonos en la descripción de los topos (selva, corporalidad femenina, campo, ciudad, guerra) y la recepción de un texto o un enjambre de estos problematizan nuestra modernidad en la era neoliberal argentina. En esta presentación realizaré un primer acercamiento, a modo de ejercicio heurístico, cuyo objetivo es visibilizar una nueva vía para ingresar a este objeto de estudio. Historia del género, historia del crimen en el arte criminal, historias de la Historia, memoria en el presente, arte y responsabilidad están atravesadas por las nuevas formas de pensar las masculinidades en los relatos criminales. En esta dirección, emoción, mujeres y masculinidad son indisociables.

Me centraré en dos novelas policiales Noxa de Inés Krimer, publicada en el 2016 y Segunda vida de Guillermo Orsi, del 2011. El ordenamiento en fechas de publicación no es azaroso ya que he preferido partir de una publicación reciente pero que, sin embargo, posee puntos de contacto con el texto de Orsi en lo tocante a las posibilidades que brindan para leer la masculinidad hegemónica y las posibles respuestas que la interpelan en las novelas seleccionadas. Siguiendo a Connell, la masculinidad hegemónica: "puede definirse como la configuración de la práctica de género que incorpora la respuesta aceptada, en un momento específico, al problema de la legitimidad del patriarcado, lo que garantiza (o se considera garantizado) la posición dominante de los hombres y la subordinación de las mujeres" (117); la masculinidad hegemónica es de carácter sistémico, un punto central del patriarcado que articula las formas de economía del neocapitalismo argentino (agrario y narcoagrario).

Es decir, mi propuesta parte de las nuevas formas de entender lo económico, del debate originado en la explotación de las riquezas naturales, formas de cultivos, fumigación y exterminio tanto en la era de las democracias como el referido caso Malvinas, resto del modelo Estado nación dictatorial. Si partimos de los textos seleccionados, la democracia y la guerra no están ajenas al ejercicio de dominación de la mujer y las formas de resistencia interpelante en las historias narradas. Esta vía de análisis implica también el carácter sociohistórico del crimen y de los géneros, lo que habilita también pensar otras masculinidades. Connell señala que estas implican "relaciones de alianza, dominio, subordinación. Estas relaciones se construyen a través de prácticas que excluyen e incluyen, que intimidan, explotan, etc. Así existe una política de género de la masculinidad” (61).

Por otra parte, considero que la historia del crimen alcanza en el nuevo milenio una multiplicidad de artefactos, no solo artísticos, sino que el crimen satura la red del tejido social en las noticias de gran impacto en lectores y telespectadores, etc. 


\section{Adiós a las armas}

Despatriarcar América desde la cultura

Asimismo, cabe preguntarse por qué la novela policial se ha convertido en un género de fuerte visibilidad y si esto está relacionado posiblemente a un lectorado que busca en las historias un algo más que el mero entretenimiento. Incluso algunos de los autores son periodistas como Juan Carrá, Hugo Salas, Javier Sinay, Mariano Hamilton, entre otros; una cuestión importante para señalar es que el relato de la inseguridad a gran escala surge en programas televisivos en diversos canales como TN, Magazín o C5N; es decir, inseguridad y crimen forma parte de la vida cotidiana argentina, son hechos como los femicidios y el narcotráfico reproducidos en los medios y cuyas consecuencias es complejo cualificar. La novela y la poesía recogen la palabra ajena, el plurilingüismo alojado en esos géneros primarios como la noticia y los recrean, al tiempo que invitan a la interpelación. Nuevas editoriales pequeñas o no tanto, producen un hacer con el crimen.

\section{Noxa, de Inés Krimer: de daño en daño}

La misoginia en las novelas negras o duras en los albores del siglo XX, desde Raymond Chandler y Dashaell Hammett en adelante, ha sido una de las constantes del género; también el siglo XIX con Eduardo Ladislao Holmberg confirió a la tradición policial en "La bolsa de huesos" un ejemplo del poder masculino y las tretas de la mujer para evadir los sistemas de control social. Las leyes en el siglo citado, la filosofía positivista y los usos y costumbres en nuestras sociedades relegaban a la mujer de roles profesionales, derecho al sufragio, etc. Dichos logros se llevarán a cabo de modo paulatino en el siglo XX argentino con mujeres como Alicia Moreau de Justo y Eva Perón, respectivamente, quienes supieron obtener para las mujeres, los derechos de una ciudadana visible. Sobre el catecismo estético, el rol del detective con determinada fisonomía literaria hizo del hombre duro un culto a seguir. Pero además con la presencia de la mujer partenaire con escasas dotes intelectuales y profesiones específicas como la de secretaria, o bien prostituta o amante ocasional fueron parte del género; una alquimia masculino femenino que permitió poder leer nuestro lugar en la sociedad desde una fórmula que sale a la calle para fortalecerse, alejado del mero entretenimiento. Este tuvo su fundamento en las sociedades en proceso de modernización en los países que conforman las Américas. Es decir, que es posible analizar el lugar de la mujer en la esfera social a partir de las ficciones policiales y no solo con la publicación de obras escritas por mujeres en América Latina, hecho registrado desde la década de los 80 del siglo pasado en adelante.

Más allá de quien escriba es notable que su representación ficcional de las últimas décadas del siglo XX deja ver un resquebrajamiento de la masculinidad hegemónica-patriarcal y la alianza que esta posee con modelos económicos en los cuales anida formas de colonialismo sistémico; en él, y en nuestro corpus es posible observar un archipiélago a modo de desprendimiento de sentido de la guerra de 
Malvinas como ocurre en Orsi. Realizo esta acotación porque en su texto, si bien no transcurre en las islas, es posible advertir que la historia narrada es un resto de aquella en la cual emergen las modulaciones de una emocionalidad que rompe los parámetros de lo masculino, en este caso, articulado con haber hecho la guerra y dedicarse en el presente del relato a la delincuencia.

Asimismo, entre los textos de Krimer y Orsi existe un hilo de continuidad a partir de recrear el conflicto del campo; este detonante implica tonos en el tratamiento, pero donde la masculinidad hegemónica es vulnerada a través de recreaciones que sabotean un sentido único no solo de aquella sino también del crimen. Dicho sabotaje es la vía de acceso para analizar las emociones, las mujeres, el patriarcado, etc. En la historia de un grupo de sobrevivientes de Malvinas la masculinidad hace blanco en el dispositivo que la creó, es decir, el Estado. Este también construyó el sentido épico en una guerra desigual que es recordada por los personajes de Orsi a partir de restos de una memoria en la cual la épica adquirió la forma de injusticia y de exterminio de la dictadura cívico militar eclesial argentina.

En lo tocante a la obra de Krimer, Noxa se desarrolla en el interior del país, en la cultura agraria, con lo cual el gesto de crear una localidad ficcional mueve el mapa del policial que, salvo escasas excepciones, se ambienta en su mayoría en los centros urbanos. Sin embargo, este matiz no es casual ya que es posible advertir que la modernidad, en términos de tecnologías, ha alcanzado un grado de progreso importante ante la implementación de maquinarias y fórmulas químicas para producir mayor rentabilidad en los sembrados, en especial de la soja. En la actualidad, si recorremos el paisaje campestre observamos que el rostro del progreso también se inscribe en edificios que rompen con la imagen plana, en meseta, común al campo. En esta dirección, la periodista Marcia Meyer viaja al interior del país, del cual es oriunda en busca de su amiga de la adolescencia, Ema Grinberg, que en el presente del relato se desconoce su paradero. Este centro, núcleo de la historia, se complejiza porque la búsqueda de la mujer con quien había mantenido contacto, conduce a la periodista investigadora a reconstruir la trama de la desaparición; en ella su amiga es una activa militante a favor de la protección de la naturaleza frente a la explotación indiscriminada de los suelos y los mecanismos espúreos de unos pocos, entre los que se cuenta Fernando Valverde, dueño de campos, amante ocasional de Ema Grinberg.

Es posible inferir que la historia se ambienta en el período post 2000, momento en el cual se intensifica la economía agraria con las nuevos dispositivos tecnoquímicos y el debate en la sociedad argentina que alcanzará su punto más álgido en el año 2008 con la Resolución 125; ${ }^{2}$ en esta dirección infiero un aspecto revelador del

2 El 11 de marzo de 2008 la presidenta de la Nación argentina, Cristina Fernández de Kirchner, presentó las retenciones móviles a la soja y al girasol a través de la Resolución 125/08. Fue un proyecto del gobierno argentino de recaudar sobre un sector de la economía (el sector agropecuario) que estaba 


\section{Adiós a las armas}

Despatriarcar América desde la cultura

género no solo por el topos en el cual se desarrolla sino en la asunción de tradiciones literarias puestas en cuestión a través de los comentarios de la periodista, quien es narradora básica del relato. El espacio del interior como escenario bucólico y la exaltación de cultura aparece en la figura del pintor Florencio Molina Campos cuyos cuadros costumbristas son retraducidos en esta novela; también cabe destacar la importancia de la corriente inmigratoria de fines del siglo XIX y XX en la pampa húmeda donde los gauchos judíos aportaron una cultura que reconfiguró el espacio mestizando las culturas. La inmigración judía opera en el relato como un aspecto central para entender la articulación sistémica de la masculinidad con nuevas formas de explotación económica. Es decir, Marcia enuncia al menos una doble condición: de mujer y judía, constante en la obra de Inés Krimer; dicho aspecto implica el trastocamiento de la relación entre el crimen, las emociones y las masculinidades, ya que Marcia Meyer ocupa en el mundo profesional lugares de la masculinidad hegemónica para destotalizarlos; esto implica que la mujer del relato negro moviliza la investigación y se atreve a vulnerar los lugares comunes del género interviniéndolo y esta operación implica también visibilizar su capacidad de hacer en el nuevo milenio.

La mujer en este policial horada varias dimensiones: la colectividad judía, cuando cuestiona a los miembros de la comunidad que permiten la siembra y las in-

embolsando para sí una renta extraordinaria. Renta que no le correspondía a ese sector, sino al país ya que las ganancias espectaculares que recibían, no era propias de su actividad, sino de una combinación de precios internos bajos y alza especulativa de los precios internacionales de los cereales. Esas ventajas comparativas (que se tradujo en convertir a la agricultura en el sector de la economía que más rentabilidad obtenía -muy por encima de otros sectores- la logró el país, no los agricultores). El gobierno para corregir esa asimetría, intervino dictando la Resolución 125, con la cual se pretendía recaudar una parte de esa renta agraria y evitar la distorsión de los precios internos, ya que en ese escenario mundial, se podría llegar a disparar los precios de los alimentos que consumimos. Con precios internacionales tan altos, poco tardarían en verse reflejados esos precios en los alimentos de consumos básicos. Esta es la famosa Resolución 125. Dos días después de presentado el proyecto comenzaría un paro agropecuario que duraría 129 días. La medida puso al país al borde del desabastecimiento, desnudaría los problemas del campo, y dividió a la sociedad argentina entre aquellos que apoyaban el modelo kirchnerista de aquellos que defendían el modelo agroexportador. Fue de un "lock out" de las patronales. La Resolución 125 también provocó la salida del entonces ministro de Economía, Martín Lousteau (autor de la polémica medida) y el alejamiento definitivo del Poder Ejecutivo del entonces vicepresidente de la Nación, Julio Cleto Cobos, con su recordado voto "no positivo" en el Senado. La decisión del ex titular de la Cámara Alta marcó para la década kirchnerista una de las pocas batallas donde debió aceptar la derrota. Para plantar la bandera de la resistencia las cuatro principales asociaciones nacionales de productores agropecuarios: la Sociedad Rural Argentina (SRA), la Federación Agraria Argentina (FAA), las Confederaciones Rurales Argentinas (CRA) y CONINAGRO, se unieron para conformar la llamada Mesa de Enlace. No pasó mucho tiempo para que la medida de fuerza evidenciara el pacto entre los líderes de la oposición, los dirigentes rurales y un tercer actor, que fue el grupo Clarín y otros medios de comunicación, se gestaran en el aire sobre un intento de desestabilización al gobierno kirchnerista. Durante el tiempo que duró el paro se interrumpieron algunas actividades económicas, hubo cortes de ruta en todo el país, tractorazos, bloqueos al paso de los transportes de carga y de pasajeros y se bloquearon las exportaciones agrarias. Además, se volvió a una vieja práctica: los cacerolazos. 
toxicaciones, el rol profesional y los lugares comunes que concibe a la mujer en paradigmas dicotómicos, es decir, o se es profesional o madre ya que la imagen materna, construida bajo los valores del rito mariano, es también un constructo de la masculinidad hegemónica. Dichos lugares comunes son puestos en el centro de la cuestión en la historia de la narradora con su hija Vera; lejos de ser una historia subsidiaria al eje central es una madeja textual que es preciso desandar para comprender el juego de las alianzas.

El sabotaje antes citado es posible analizarlo si recuperamos el giro emocional, las emociones como construcción político cultural, como lo señala Ahmed, que se hace en el texto a partir de la detección de los signos que arman la red emocional; en esta dirección es interesante señalar la importancia de este tipo de novelas tan cercanas a la política como el conflicto del campo y que, al mismo tiempo, forma parte del régimen narrativo. Así los cortes de rutas en el campo que pueden estar ambientados en Chaco, presididos por Ema y por otra parte, la investigación, con Marcia quien ocupa el lugar del detective, desmontan los mandatos patriarcales; una mujer que se aleja de su hija, tiene amantes y goza, señala que el lugar de la erótica está puesto en la narradora. Marcia confiesa en el pasaje amoroso con Diego Rivero:

Lo acaricio mientras le beso las tetillas. Me incorporo y le busco la boca. Me mira mientras me subo sobre él, le hundo la cara en el cuello. Cuando terminamos me quedo con la cabeza reclinada sobre su hombro. Empiezo a imaginar su llegada a casa, los comentarios sobre pacientes mientras me pasa la mano por el culo o mis pellizcos mientras él lava los platos, descreo de la rutina tratando de hacer de mi una puta, no hay satisfacción en eso fingiendo disfrutar hasta que él se corre y entonces lo termino yo misma de cualquier manera con todas las maravillas que dice la gente es solo la primera vez. después es nada más lo corriente, todo pasa por mi cabeza mientras él aumenta la presión del brazo. Date vuelta, dice. Giro. Siento el peso de su cuerpo mejor que se lo meta por atrás del modo que lo hace la señora Mastiansky, me dijo que se lo hacía hacer su marido como los perros y sacar la lengua y él tranquilo y manso nunca se sabe con los hombres la manera como les agarra (Krimer 133-134).

Es interesante advertir en esta cita cómo la narradora goza al mismo tiempo que lucha contra los mandatos y lugares comunes acerca del goce erótico, incluso con las fantasías en la cual el varón lava los platos, la vida rutinaria de la pareja tradicional, con actividades comunes. Diego Rivero, el amante de Marcia, nos hace advertir que existen diversas formas de masculinidades, tejidas en relación de alianza no solo con la mujer sino también en las formas de hacer política en su calidad de médico y militante social. El médico no solo atiende los casos de toxicidad, sino que su accionar convierte su profesión en un acto de resistencia. 


\section{Adiós a las armas}

Despatriarcar América desde la cultura

Un aspecto importante que anuda las nuevas formas de análisis para estos objetos de estudio tan cercanos a nuestra realidad cotidiana son sin dudas los cuerpos echados a perder por efecto de la toxicidad. Marcia descubre un asesino invisible, cercano al tratamiento que Guillermo Orsi realiza del jefe de la banda de ladrones a sueldo, cuyo rostro no alcanzan a identificar o duda de ella, como observaremos en el análisis. Es el poder el que promueve el crimen invisibilizado por los miembros de la comunidad. Así, desde la perspectiva de Sara Ahmed las emociones determinan el valor de los sujetos, su mayor o menor importancia, la distancia de unos con otros. Es decir, son las emociones las que rigen la vida cotidiana, los espacios públicos en los cuales nos movemos, y también las resimbolizaciones como el arte. De allí la importancia que posee la articulación entre los estudios literarios con marcos teóricos que nos permitan poner en valor aspectos que no emergen a simple vista.

En ambos textos es el diseño del Estado nacional el ideologema al cual se interpela; es posible inferir cómo la política hace signo en los cuerpos ya que todo cuerpo vive expuesto y dicha exposición implica también formas de negociaciones múltiples y reticulares de unos con otros entre los cuales se desplaza el Estado. Es decir, no solo vivimos en un Estado, sino que este y su historia nos atraviesa en la vida cotidiana. Y es el conjunto de usos y costumbres de la vida de campo en Argentina post 2001 lo que evidencia un diseño de proyecto neoliberal; este deja ver que la mestización con la lengua idish, deconstruye la épica de la inmigración judía olvidada con las prácticas de ocultamiento y silencio acerca del envenenamiento masivo no solo de quien preside el museo, Osías, sino de la comunidad judía. Por lo tanto, son varias las comunidades colapsadas en el texto, como la criolla, la judía, los lugares como los hoteles, espacio de la transitoriedad en el cual Marcia puede gozar como ocurre con el microrelato del visitador médico.

\section{Los cuerpos: de la erótica a la mancha}

Las colectividades y la emocionalidad con su carácter político son centrales en el texto de Krimer. ¿Cómo se resuelve esta dimensión en una ficción criminal? Sostengo que el lugar de enunciación es un aspecto central, ya que el relato policial se ha caracterizado en su versión clásica y negra por el predominio de la primera persona. No es casual que en el texto de Krimer la historia comience con la primera persona y que, a lo largo del relato, podamos captar otras voces, la de un nosotros; el colectivo puede ser el del agresor y el enjambre de personajes agresores o los vulnerados. Llevado al terreno de las emociones y su relación con la literatura podemos inferir que Noxa es un relato en primera persona, pero lo que cuenta, deviene en colectivo y este doble estatuto produce en los lectores identificaciones que provienen del campo socio político. Es decir, la búsqueda 
de su amiga, la militancia, el enamoramiento, la existencia de hijos deformes o la muerte de niños y mujeres, producto del envenenamiento masivo y de intereses de grupos económicos, son temas de la vida cotidiana argentina. Marcia es una mujer profesional, como muchas, que trabaja para un medio gráfico, que busca la verdad en la noticia y que también compite con los mandatos de Juan, el director del periódico. Sin embargo, lo singular en el texto es que la historia individual se trama en relación a Ema que encarna la resistencia en el pueblo y que otrora fue amante de Pablo, su ex esposo.

La resistencia política y los cuerpos manchados por la infección de agroquímicos constituyen el eje del crimen, en consecuencia, la imagen de los cuerpos marcados es un efecto político. La mancha marca, señala los cuerpos que en la economía del sembrado son abyectos, cuerpos de niños que hay que aislar como el caso de Tomi, hijo de Ema, y madres que hay que desaparecer. He aquí otro de los aspectos centrales como son los femicidios y la violencia de género, como el caso de María Ordóñez quien entierra a su hijo de dos años por temor a que pareja se violente con ella. En consecuencia, se advierte que con el final de las historias no culminan los textos. Éstos dejan un espacio de sentido abierto con los finales que muy bien pueden leerse en la coordenada social; esas historias pasan a formar parte de otras tantas de las que transcurren en nuestra sociedad. No se trata de la apuesta de los autores con el verosímil, sino que las narraciones proponen contarnos historias que son parte de experiencias compartidas, al momento que hemos vivido, son parte del pasado y del presente. Esto implica que una novela dividida en veintinueve capítulos con un prólogo que forma parte del régimen ficcional culmine con "Una nota de la autora" en la cual explica el alcance, la peligrosidad del glifosato/Noxa/daño. En dicha nota aclara también que su novela está integrada, con variantes, por textos dedicados al estudio del herbicida y la salud. Es decir, estamos frente a un proyecto de escritura que parte del territorio histórico presente con el cual se produce la ficción.

No hay una masculinidad en la nueva novela negra sino masculinidades interpelantes y estas potencian y hacen visible que en el campo conviven diversas colectividades organizadas por alianzas económicas. En consecuencia, la alianza económica y la masculinidad hegemónica es un efecto del patriarcado, bajo el rostro de una nueva colonialidad, la del poder económico. Las manchas que muestran los cuerpos enfermos conforman una heterotopía, bajo la luz de una lente que muestra lo masculino y lo económico como una agresión al cuerpo social. Son las mujeres como Ema, Marcia y María Ordóñez, las manchadas que nos interpelan desde el texto. De modo tal que el regreso a la capital de Marcia, sus manchas en la piel y su embarazo al culminar la novela construyen un final abierto ya que no hay justicia ni denuncia posible frente al crimen masivo. El texto deja ver a Diego Rivero, el médico amante de Marcia, que también desarma la hegemonía masculina, la interpela al organizar y participar en los cortes de ruta. 


\section{Adiós a las armas}

Despatriarcar América desde la cultura

En esta dirección, el policial del nuevo milenio hace audibles historias, no solo verosímiles, sino sobre todo constituyen la recreación de temas que nos afectan y emocionan, con los cuales podemos o no identificarnos, pero frente a los cuales no somos indiferentes. Infiero que la intersubjetividad es una vía de acceso a la política de y con las emociones que es posible advertir en la historia en Noxa; las emociones promueven a nivel de historia una nueva forma de leer el paradigma civilización-barbarie, ya que el carácter bucólico del campo se quiebra por efecto de nuevas formas de entender el crimen. Igualmente, interesante es el uso de imágenes poéticas, libros mencionados por Marcia como la novela de Albert Camus La peste, o la obra de Roberto Arlt, la lengua idish que aporta un aspecto central a lo que es el imaginario de la inmigración y una lengua menor que rompe con el relato de la identidad argentina.

\section{Las masculinidades postguerra Segunda Vida, de Guillermo Orsi}

Uno de los aspectos más significativos de la novela de Orsi, publicada en el año 2011, es la dimensión del crimen, las emociones y la masculinidad postguerra de Malvinas como parte central de la narración. La historia de ex soldados en el frente bélico, dedicados a la delincuencia en la democracia con acento en la crisis del 2001, es el punto central de la historia; en la novela se traza el paralelismo bajo la forma de trabajo de la memoria con respecto al tiempo presente, cuando los excombatientes son contratados para un robo a gran escala en el campo llamado Maizales, y el pasado, ubicado en las islas. Si partimos de este doble anclaje del crimen podemos considerar a los personajes simultáneamente como soldados y excombatientes. En consecuencia, un análisis del campo literario que advierta la articulación entre crimen, masculinidades y emociones puede estar encaminado a potenciar no solo los personajes sino también de cómo el sentido de la heroicidad épica de la guerra es cuestionada desde la literatura; la exaltación épica de la dictadura, el olvido de las democracias de los ochenta y noventa en adelante constituyen, desde mi perspectiva, el centro valórico del texto. Es el relato de la comunidad imaginada nación junto con las consecuencias que genera una guerra injusta la que sostiene la historia de los criminales. Sin la guerra de Malvinas3 no es posible comprender cabalmente la historia narrada.

La narración recuerda tramos de la historia de los soldados en las islas y en el presente del relato el campo, la selva, la capital del país con acento en la Villa 31 conforman una cartografía del crimen, en la cual la corrupción del Estado argenti-

3 La guerra de Malvinas se desarrolló entre el 2 de abril y 14 de junio de 1982 en la cual Argentina pierde el dominio geopolítico, la soberanía de las islas frente a Reino Unido de Gran Bretaña. La milicia argentina estaba constituida en su mayoría por soldados que desconocían cómo llevar a cabo la guerra. Asimismo, la conformación soldadesca la integraban en su mayoría jóvenes del Norte y Centro argentino. 
no atraviesa el cuerpo de los soldados y excombatientes. El texto está constituido por tres partes y un epílogo: "Vidas silvestres", "Combates y Armisticios" y "Sigue Malvinas".

La guerra de Malvinas movilizó el pueblo en las calles, la sociedad deseaba ir a la guerra, al tiempo que el Estado necesitaba emerger de una crisis en la cual la violación de los Derechos Humanos con treinta mil desparecidos y niños sustraídos habían tomado estado público internacional. No es casual que en el capítulo primero el narrador exprese: "Cuando volví de Malvinas creí que el pueblo argentino estaría en las calles” (Orsi 15). Una exaltación nacionalista se registraba en las calles, en abril de 1982, el pueblo se movilizaba en busca del triunfo que no fue tal. La guerra no solo produjo muertes en el campo de batalla sino también nuevos desaparecidos. El relato narrado por El porteño es un acto de una memoria lacerada sobre Malvinas y sus consecuencias en los sobrevivientes, cuyos derechos no fueron reconocidos como soldados de una guerra injusta sino hasta el nuevo milenio. ${ }^{4}$ De allí que la novela de Orsi es la narración de una doble historia, las causas y las consecuencias de la guerra en la cual las masculinidades en pugna evidencian lo que de modo residual posee el género negro, a saber, la construcción femenina de Samantha, en su rol de amante, la tía Kof Kof y otras mujeres como diferentes prostitutas que aparecen en el texto, al tiempo que la primera vulnera el modelo cuando se alía con la comunidad mataca en la consecución de los intereses del grupo de indios y de los propios. Asimismo, también es preciso mencionar la historia de amor que se adelanta en el primer capítulo y encuentra resolución en el epílogo entre El Porteño y la trabajadora social que asiste en el año 2001 los comedores colectivos como signo del derrumbe económico en el país. Nuevas profesiones, mujeres concebidas más allá del amantazgo y hombres que hacen la guerra sin las islas como el excombatiente Rulo Pereyra, convertido en el presente del relato, en una máquina de matar construyen Segunda vida como la narración de las emociones que giran en torno a la derrota.

La muerte y la delincuencia postguerra son una nueva forma de la economía neoliberal ya que Platón, el Turco, y el Porteño se dedican, hasta el momento que son contratados por Sandoval y Paz Alcorta, a los asaltos pequeños, al menudeo. La propuesta de trabajo por encargo evidencia que la delincuencia articula la siembra de soja y el tráfico de cocaína como una nueva forma de economía en el nuevo milenio al tiempo que esta actividad delincuencial es otra forma difusa de

4 Eduardo Manero señala que fueron los gobiernos de Néstor y Cristina Fernández de Kirchner respectivamente los que reabrieron el caso Malvinas en la esfera política y pública como parte de la agenda de los derechos humanos, luego de un largo silenciamiento, el denominado proceso desmalvinización, en la década de los noventa. En la era del Menemato es importante destacar que la reivindicación de Malvinas se restringió a las demandas de los excombatientes y a expresiones políticas minoritarias nucleadas en torno de diversas concepciones del nacionalismo ya sea de izquierda (PC y PCR), centro (Frente Grande) y derecha Carapintada. 


\section{Adiós a las armas}

Despatriarcar América desde la cultura

la masculinidad. Se necesita la fuerza del cuerpo de los excombatientes y estar al margen de la ley, pero en alianza con sujetos que la representan, ya que Sandoval y Paz Alcorta son parte del cuerpo policial. De modo tal que el crimen es susceptible de ser leído como crimen de guerra y de las consecuencias de la guerra. Si partimos de esta hipótesis de lectura es el Estado, dictatorial y neoliberal, el autor intelectual del crimen.

Como acoté más arriba, en el texto se desplaza un tono emocional de derrota sobre todo en el Porteño que es también narrador; impotencia, bronca y venganza de carácter sociohistórico son los tonos que no es posible soslayar al estudiar las emociones en la literatura. Desde el comienzo se advierte que los personajes esperaban el reconocimiento del pueblo quien se mantuvo indiferente ante el regreso, como ocurre con los cortes de rutas en la novela de Krimer. En consecuencia, el tono personal es político porque allí se aloja la impotencia. El delito así posee en la diégesis un aliento sociopolítico en la cual también resalta la valoración hacia la mujer cuyas descripciones físicas provienen de una voz masculina que posee tonos diferentes; estos abarcan la peyorización, en la significación hacia la mujer como menopaúsica, es decir, el devenir de las mujeres a lo que se conoce como "adultas mayores" tal como sucede con El Porteño; en el microrelato del incendio de La Granja, lugar para jóvenes recuperados, el personaje repite "menopáusica" como metonimia de las mujeres mayores y por consiguiente "descartables". O bien Samantha que se convierte en objeto sexual, al servicio del goce masculino: “¿¿Qué vamos a hacer con Samantha?/-Cojerla. Qué otra cosa se puede hacerse con Samantha" (147). El diálogo se entabla entre Sandoval, el comisario, y El Porteño. Otro pasaje revelador es el microrelato referido al El Jardinero, el único delincuente que no fue a Malvinas, en el cual el narrador alude a la historia de cómo su amigo prendió fuego a su mujer. También cabe mencionar que el narrador es padre de un hijo no reconocido. De modo tal que hay un espacio paterno no cubierto que lo obsesiona; dicha condición moviliza tramos de emoción en la esfera de lo masculino que hace que el personaje obediente a una masculinidad hegemónica sea vulnerado por la memoria que devuelve imágenes del hijo o por el discurso amoroso puesto en las imágenes de la mujer de la cual se enamora, llamada Dolores. Aquí también se conjuga otra derrota. Es decir, estamos frente a hombres cuya emocionalidad los ubica en una línea de frontera, hacen la guerra, son delincuentes y algunos femicidas. Estamos frente a diversas masculinidades hechas de alianzas (Samantha), subordinación (delinquen y dependen de un jefe, hicieron la guerra, etc). Esta dimensión explica la mezcla de tonos narrativos de El Porteño cuando, desde el presente del relato, acude al discurso amoroso y simultáneamente al dolor de un sobreviviente de la guerra; observemos la confesión:

Valdrá la pena haber sobrevivido nada más que por escribir tu nombre sobre la arena, fíjate qué romántico pelotudo puede volverse un veterano de Mal- 
vinas al que nadie esperaba cuando regresó al continente. Después de que a su inmediato alrededor media docena de mis compañeros -y media más, de otros que no lo fueron tanto- volaron despedazados, mutilados, envueltos en las mortajas de sus alaridos finales, dieciocho años recién cumplidos, criados, la mayoría, a pura manola y soledades, pibes a los que su propio país acostó sobre el altar del sacrificio (144).

Cabe advertir en la cita un horizonte de sentido construido a partir de la intimidad del yo, pero que sin el recuerdo de la guerra y del abandono en la imagen del sacrificio colectivo no es posible entender la soledad del presente del narrador protagonista. En consecuencia, el discurso amoroso y los hechos colectivos son indisociables y traman el carácter emocional del texto. Asimismo, en tramos precisos, los lectores asistimos a escenas que bien pueden haber sucedido en Malvinas como en la selva mesopotámica donde transcurre parte de la historia.

\section{La economía de la emoción, lo masculino y el noir}

Escribir Malvinas en clave de novela negra es poner en cuestión los modos de representación del crimen, del Estado y de los sujetos. Asimismo, como herida abierta, espacio de problematización de la memoria, implica también recuperar el pasado para que ilumine el carácter inconcluso no solo de aquel (dictadura, Malvinas, posdictadura) sino el horror de la historia reconvertida en un presente como un tiempo donde esos acontecimientos hacen colapsar los modos de leer una ficción y su relación con la historia. Es en este punto donde las emociones son construidas y reconstruidas, ya que los exsoldados no son solo asesinos estéticamente creados para el género policial, sino que este los aloja porque hay heridas no cerradas en el presente argentino que nos atraviesan como lectores. Orsi recupera la fórmula de guerra, disparos, perseguidos, asesinatos, mujeres al borde de la fórmula y construye un cúmulo emocional donde también los lectores armamos un relato a partir de las huellas de lo social en el texto; todos esos componentes del género son la materia creada que recoge los hechos históricos narrados desde otro lugar, alterno al del discurso histórico.

Ahmed señala que las emociones no solo son políticas sino también que los colectivos son centrales en la dinámica cultural. En esta dirección, sabemos que el caso Malvinas confirió a la literatura ficciones de calidad indiscutible desde Carlos Gamerro, Enrique Fogwill, Fernando López a Federico Lorenz, Patricia Ratto, Patricio Pron y Sergio Olguín, entre otros. En esta secuencia hay que ubicar la novela de Orsi que forma una serie desde la cual me interesa resaltar que las emociones, la mujer y las masculinidades no se resuelven solo en la historia de amor. Este emerge en ella pero es un hecho histórico el que moviliza una red emocional en 


\section{Adiós a las armas}

Despatriarcar América desde la cultura

los personajes constituida por la falta de proyecto de los excombatientes ante el abandono del Estado; así las diferentes masculinidades asoman en el núcleo duro de la fórmula negra y son nuevas mujeres las que dinamizan el relato. Malvinas está imbricada en el presente, en el post 2000, como una refracción del pasado, del cual el narrador no se puede desprender. El despliegue en capítulos cortos y apartados produce que los lectores podamos advertir el juego pasado-presente y empaticemos con él al reconocer que lo narrado también forma parte de la realidad cotidiana de la cultura argentina. El campo estallado bajo nuevas formas económicas, la ciudad en plena crisis, los comederos comunitarios, el crimen organizado junto con la cúpula policial en una alianza delincuencial conforman un horizonte de expectativa reconocible por el lector común que deambula entre el contrato de ficción y su realidad cotidiana, que también está teñida de historicidad. En este sentido, las novelas de Krimer y de Orsi tienen de ficción tanto como de pacto con la realidad socioeconómica, al tiempo que las comunidades están desmontadas a partir de recrear un Estado que habilita el delito. Entretención, información, diversión e historia atraviesan estas ficciones.

Las mujeres aparecerán como prostitutas junto con otras, ligadas a las causas sociales; la masculinidad hegemónica representada en los funcionarios u hombres de campo o en las prácticas sexogenéricas de los delincuentes son matizadas por otras, más aliadas a las mujeres que a la sujeción de estas como es Diego Rivero de Krimer, o pasajes de El Porteño en Orsi. Entre las emociones y los colectivos el factor económico es fundamental porque el crimen en Orsi articula pobreza, necesidad, olvido, impotencia. La máquina capitalista implica la acumulación y el valor tal como lo señala Ahmed. El Jardinero es un personaje central en este sentido porque no hay resistencia ni lucha posible sino la puja por insertarse en la sociedad y acumular riqueza. Al Jardinero no le interesa cultivar flores sino hectáreas de campo, convertirse en un terrateniente; otro de los ejemplos es El Porteño que hacia el final confiesa que luego de la crisis económica integra la lista política en el peronismo bonaerense. No hay una salida hacia ninguna revolución posible, sino la anomia capitalista hecha carne en estos personajes.

\section{Conclusiones}

Ambos son textos que apelan al imaginario social. Argentina está atravesada por acontecimientos traumáticos que articulan nuestro modo de percibir la realidad y a partir de los cuales se generan debates tales como los que vehiculiza la metáfora de "la grieta". Los conflictos sociales en Krimer o la guerra de Malvinas en Orsi movilizan matices emocionales en los lectores que nos identifican en un proceso en el cual el arte de la palabra muestra una memoria inacabada en pleno dinamismo. El presente interpela al pasado, donde la naturaleza, el paisaje agrotóxico, las postales 
de islas perdidas reponen una emocionalidad lectora igualmente interpelante. Ni la economía de la siembra ni el conflicto de Malvinas son acontecimientos concluidos, tampoco lo son los femicidios; al mismo tiempo, el avance en la esfera pública señala nuevos lugares de la mujer en nuestra cultura. En este sentido, un estudio de la articulación entre la literatura y las emociones debe considerar una perspectiva interdisciplinar, por fuera de límites de los saberes estancos. Un indisciplinamiento desde la teoría literaria en la cual sea posible escuchar el diálogo, el susurro de la historia, lugar donde es posible reponer la lectura como experiencia social. 


\section{Obras citadas}

Ahmed, Sara. La politica cultural de las emociones. Universidad Nacional Autónoma de México, 2015.

Connell, R.W. Masculinidades. Universidad Autónoma Metropolitana, 2003.

Ehrmantraut, Paola. Masculinidades en guerra. Malvinas en la literatura y el cine. Comunicarte, 2013.

Krimer, María Inés. Noxa. Revolver, Argentina, 2016.

León, Emma, compiladora. Los rostros del otro. Reconocimiento, invención y borramiento de la alteridad. Anthropos, 2009.

Orsi, Guillermo. Segunda vida. Editorial Norma, 2011.

Manero, Eduardo. "La guerra de Malvinas como instrumento de regulación violenta de la sociedad. Efectos pedagógicos del disciplinamiento". Relatos de Malvinas. Paradojas en la representación e imaginario social, editado por en María Angélica Semilla Durán, Eduvim, 2016.

Parret, Herman. Las pasiones. Ensayo sobre la puesta en discurso de la subjetividad. edicial, 1995.

Revista Ensemble. La cuestión Malvinas. A 50 años de la Resolución 20065 de la ONU. Ministerio de Educación de la Nación Argentina y Casa Argentina en París, 2015.

Rodríguez Elizondo, José. Guerra de las Malvinas. Noticias del desarrollo 1982-2012. El Mercurio/Aguilar, 2012. 